Article

\title{
Enzyme-Catalyzed Synthesis of Unsaturated Aliphatic Polyesters Based on Green Monomers from Renewable Resources
}

\author{
Yi Jiang ${ }^{1,2}$, Albert J.J. Woortman ${ }^{1}$, Gert O.R. Alberda van Ekenstein ${ }^{1}$ and Katja Loos ${ }^{1,2, *}$ \\ 1 Department of Polymer Chemistry, Zernike Institute for Advanced Materials, University of \\ Groningen, Nijenborgh 4, 9747 AG Groningen, The Netherlands; E-Mails: Y.Jiang@rug.nl (Y.J.); \\ A.J.J.Woortman@rug.nl (A.J.J.W.); G.O.R.Alberda.van.Ekenstein@ rug.nl (G.O.R.A.E.) \\ 2 Dutch Polymer Institute (DPI), P.O. Box 902, 5600 AX Eindhoven, The Netherlands \\ * Author to whom correspondence should be addressed; E-Mail: K.U.Loos@ @rug.nl; \\ Tel.: +31-50-363-6867; Fax: +31-50-363-4400.
}

Received: 15 July 2013; in revised form: 31 July 2013 / Accepted: 1 August 2013 /

Published: 12 August 2013

\begin{abstract}
Bio-based commercially available succinate, itaconate and 1,4-butanediol are enzymatically co-polymerized in solution via a two-stage method, using Candida antarctica Lipase B (CALB, in immobilized form as Novozyme $\left.{ }^{\circledR} 435\right)$ as the biocatalyst. The chemical structures of the obtained products, poly(butylene succinate) (PBS) and poly(butylene succinate-co-itaconate) (PBSI), are confirmed by ${ }^{1} \mathrm{H}$ - and ${ }^{13} \mathrm{C}-\mathrm{NMR}$. The effects of the reaction conditions on the CALB-catalyzed synthesis of PBSI are fully investigated, and the optimal polymerization conditions are obtained. With the established method, PBSI with tunable compositions and satisfying reaction yields is produced. The ${ }^{1} \mathrm{H}-\mathrm{NMR}$ results confirm that carbon-carbon double bonds are well preserved in PBSI. The differential scanning calorimetry (DSC) and thermal gravimetric analysis (TGA) results indicate that the amount of itaconate in the co-polyesters has no obvious effects on the glass-transition temperature and the thermal stability of PBS and PBSI, but has significant effects on the melting temperature.
\end{abstract}

Keywords: enzymatic polymerizations; CALB; unsaturated aliphatic polyesters; bio-based monomers; succinate; itaconate; 1,4-butanediol; renewable resources 


\section{Introduction}

Utilizing renewable resources for the replacement of depleting fossil stocks is an appealing research topic, both in the academic and industrial areas [1-5]. It is a promising approach to solve the severe environmental problems induced by the increasing petroleum consumptions nowadays and the plausible energy shortage in the future. As abundant carbon-neutral renewable resources, biomass stocks are generated directly from solar energy in a short cycle. A great number of monomers and macromonomers can be produced from biomass stocks by natural biological activities or chemical modifications [6,7]. These bio-based monomers provide numerous opportunities for the synthesis of green and novel polymers.

Unsaturated polyesters are widely used as thermosetting resins in various industrial areas [8-10]. They are usually produced by polycondensation of diacids and diols based on petroleum stocks, using titanium or tin alkoxides as catalyst [11]. The synthesis temperature is usually above $150{ }^{\circ} \mathrm{C}[11,12]$. Many monomers with chemically or thermally unstable moieties are not suitable for polyester synthesis, due to uncontrollable side reactions induced by such a high temperature, like gelation, decomposition and discoloration [11-13]. Besides, the residual metals from the conventional catalysts are hard to remove, which may cause undesirable pollution upon disposal [12].

Candida antarctica Lipase B (CALB) is a very versatile biocatalyst for polyester synthesis, working with various monomers and organic solvents under mild conditions [12,14-27]. CALB-catalyzed synthesis of polyesters from green monomers has recently gained increasing popularity. Succinate [28-31], fatty acids from plant oils [11,32-37], isosorbide [29,30] and 1,4-butanediol [8,28,31,38-40] are extensively studied. The bio-based polyesters produced are eco-friendly, since the monomers and the catalysts are all generated from renewable resources, and the polymers are biodegradable $[9,28,39]$.

Itaconate is a commercially available green bio-based monomer. Its acid derivative, itaconic acid, has been industrially fermented from carbohydrates using Aspergillus terreus since the 1960s [41]. This monomer has interesting photoactive and biocompatible properties [9]. It is an ideal building block for constructing unsaturated polyesters with potential biomedical and engineering applications $[9,42,43]$. However, up until now, itaconate has not been well studied for polyester synthesis, neither by conventional catalysts nor by biocatalysts. Limited kinds of itaconate-based polyesters were synthesized using conventional chemical catalysts [8-10,43-48]. Only two papers referred to the enzymatic polymerizations of itaconate with other monomers: Barrett et al. reported enzymatic co-polymerizations of dimethyl itaconate and adipic acid with 1,4-cyclohexanedimethanol and poly(ethylene glycol) [9]; and Rajkhowa et al. reported Lipase-catalyzed polymerization of diglycidyl ether of bisphenol A and itaconic anhydride [49]. To the best of our knowledge, the enzyme-catalyzed co-polymerization of succinate, itaconate and 1,4-butanediol has not yet been studied. This is probably due to the low enzyme polymerizability of itaconate, which is caused by its short chain length [28] and the stereo-hindrance effect of the carbon-carbon double bond suspended around the carbonyl group. We believe CALB is the perfect biocatalyst for the synthesis of itaconate-based polyesters, due to its wide monomer adaptability, rendering polyesters in which the thermal unstable carbon-carbon double bonds could be preserved, since the enzymatic polymerization will be performed at mild temperatures under $100{ }^{\circ} \mathrm{C}[12,17]$. 
We present an environmental friendly approach towards unsaturated aliphatic polyesters. Bio-based succinate, itaconate and 1,4-butanediol are enzymatically co-polymerized in solution via a two-stage method, using CALB as the catalyst. The general synthesis strategy is illustrated in Figure 1. Monomers are oligomerized at $80{ }^{\circ} \mathrm{C}$ under nitrogen atmosphere during the first stage. Then, the oligomers are polycondensed at the same temperature under high vacuum during the second stage. To achieve the best polymerization results, the effects of different reaction conditions on CALB-catalyzed synthesis of poly(butylene succinate-co-itaconate) (PBSI) are extensively investigated, and the optimal polymerization conditions are obtained. With the method we established, poly(butylene succinate) (PBS) and a series of PBSI are synthesized. The chemical structures, molecular weight and thermal properties of the co-polyesters are characterized by different methods.

Figure 1. Candida antarctica Lipase B (CALB)-catalyzed co-polymerization of succinate, itaconate and 1,4-butanediol.

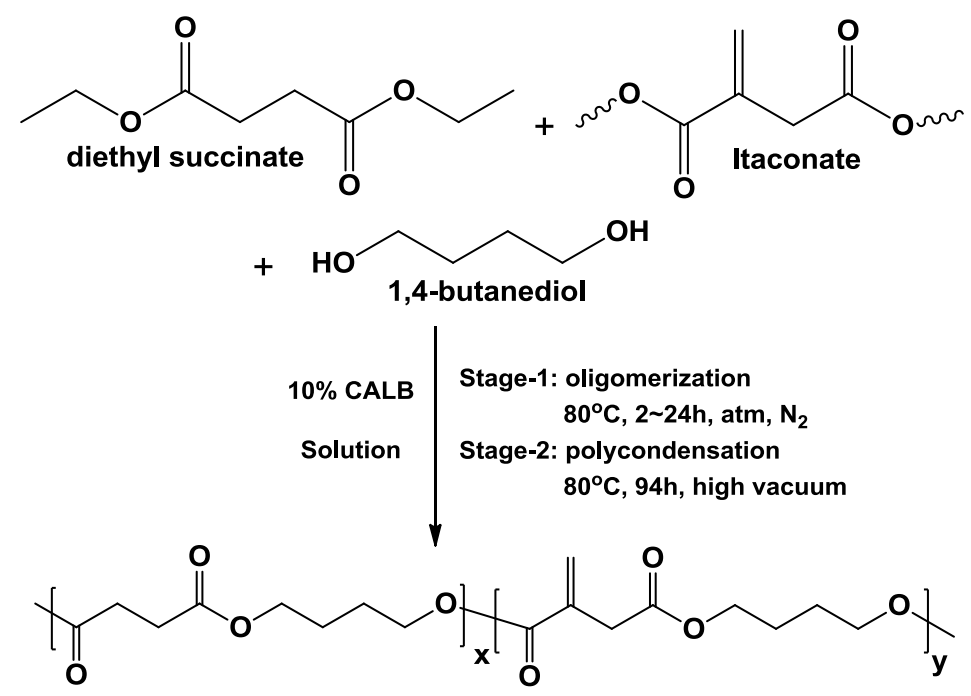

\section{Results and Discussion}

\subsection{Effects of Polymerization Conditions on CALB-Catalyzed Co-Polymerization of Diethyl} Succinate, Dimethyl Itaconate and 1,4-Butanediol

Succinic acid, itaconic acid and 1,4-butanediol are commercially available bio-based monomers. They are good building blocks for polyester synthesis. However, succinic acid has a rather low solubility in 1,4-butanediol under enzymatic polycondensation conditions, which leads to low polymerization efficiency [28]. Itaconic acid has the same problem, according to our observations reported in Section 2.2. To avoid phase separation during polymerization, diethyl succinate and dimethyl itaconate were used as the acyl donors.

For the purpose of producing PBSI with the highest amount of itaconate, molecular weight and reaction yield, the effects of several polymerization conditions on CALB-catalyzed co-polymerization of diethyl succinate, dimethyl itaconate and 1,4-butanediol were investigated, including solvent, solvent dosage, oligomerization time during the first stage and vacuum during the second stage. 


\subsubsection{Effect of Solvent on CALB-Catalyzed Co-Polymerization of Diethyl Succinate, Dimethyl} Itaconate and 1,4-Butanediol

Dodecane, diethylene glycol dimethyl ether (diglyme) and diphenyl ether were evaluated, as they have been proven to be suitable for enzymatic synthesis of polyesters [13,28,50]. As summarized in Table 1, PBSI with the highest mole percentage of itaconate $\left(\mathrm{X}_{\mathrm{I}}\right)$ and number average molecular weight $\left(\mathrm{M}_{\mathrm{n}}\right)$ was synthesized using diphenyl ether as solvent. However, the highest reaction yield was obtained in diglyme; the second highest reaction yield in diphenyl ether.

As presented in Table 1, when the molar feed ratio of dimethyl itaconate was $15 \%$, the values of product $\mathrm{X}_{\mathrm{I}}$ obtained in diphenyl ether, dodecane and diglyme were $10.5 \%, 3.5 \%$ and $0.3 \%$, respectively. The corresponding $M_{n}$ calculated from ${ }^{1} \mathrm{H}-\mathrm{NMR}$ spectra were 1,304 g/mol, $963 \mathrm{~g} / \mathrm{mol}$ and $854 \mathrm{~g} / \mathrm{mol}$. The reaction yields were $55.5 \%, 54.3 \%$ and $68.8 \%$, respectively.

Meanwhile, when the feed ratio of dimethyl itaconate was increased to $25 \%$, the values of product $\mathrm{X}_{\mathrm{I}}$ achieved in diphenyl ether, dodecane and diglyme were $15.9 \%, 3.7 \%$ and $5.9 \%$, respectively. The corresponding $\mathrm{M}_{\mathrm{n}}$ were $1,403 \mathrm{~g} / \mathrm{mol}, 730 \mathrm{~g} / \mathrm{mol}$ and $795 \mathrm{~g} / \mathrm{mol}$. The reaction yields were $22.6 \%, 18.3 \%$ and $30.2 \%$, respectively.

Table 1. The effect of solvent on CALB-catalyzed synthesis of poly(butylene succinate-coitaconate) (PBSI).

\begin{tabular}{|c|c|c|c|c|c|c|c|c|c|}
\hline \multirow[b]{3}{*}{ Solvent } & \multirow[b]{3}{*}{$\log P$} & \multicolumn{6}{|c|}{ Molar composition } & \multirow{3}{*}{$\begin{array}{c}\text { Molecular weight } \\
M_{n}(\mathrm{~g} / \mathrm{mol})^{b} \\
\end{array}$} & \multirow[b]{3}{*}{ Yield $(\%)$} \\
\hline & & \multicolumn{3}{|c|}{ Feed $(\%)$} & \multicolumn{3}{|c|}{ PBSI $^{a}(\%)$} & & \\
\hline & & $\mathbf{F}_{\mathrm{S}}$ & $\mathbf{F}_{\text {I }}$ & $\mathbf{F}_{\mathbf{B}}$ & $\mathbf{X}_{\mathbf{S}}$ & $\mathbf{X}_{\mathbf{I}}$ & $\mathbf{X}_{\mathrm{B}}$ & & \\
\hline Diphenyl ether & 4.1 & 35 & 15 & 50 & 40.5 & 10.5 & 49.0 & 1,304 & 55.5 \\
\hline Dodecane & 6.8 & 35 & 15 & 50 & 46.5 & 3.5 & 50.0 & 963 & 54.3 \\
\hline Diglyme & -1.3 & 35 & 15 & 50 & 49.2 & 0.3 & 50.5 & 854 & 68.8 \\
\hline Diphenyl ether & 4.1 & 25 & 25 & 50 & 35.3 & 15.9 & 48.8 & 1,403 & 22.6 \\
\hline Dodecane & 6.8 & 25 & 25 & 50 & 46.5 & 3.7 & 49.8 & 730 & 18.3 \\
\hline Diglyme & -1.3 & 25 & 25 & 50 & 43.2 & 5.9 & 50.9 & 795 & 30.2 \\
\hline
\end{tabular}

$F_{S}, F_{I}, F_{B}$ : molar feed ratio of succinate, itaconate and 1,4-butanediol; $X_{S}, X_{I}, X_{B}$ : mole percentage of succinate, itaconate and butylene units in PBSI; polymerization conditions: $200 \mathrm{wt} \%$ of solvent; Stage-1: $80{ }^{\circ} \mathrm{C}, 24 \mathrm{~h}, \mathrm{~N}_{2}$; Stage-2: $80{ }^{\circ} \mathrm{C}, 94 \mathrm{~h}$, vacuum $40 \mathrm{mmHg}$; ${ }^{\text {a }}$ molar composition determined by integration of the ${ }^{1} \mathrm{H}$-NMR spectra; ${ }^{\mathrm{b}}$ number average molecular weight $\left(\mathrm{M}_{\mathrm{n}}\right)$ calculated from ${ }^{1} \mathrm{H}-\mathrm{NMR}$ spectra; log $P$, logarithm of partition coefficient.

It has already been reported that diphenyl ether is the preferred solvent to achieve higher $\mathrm{M}_{\mathrm{n}}$ for lipase-catalyzed synthesis of polyesters [13,28,50], which is in good accordance with our current results. Three factors could be attributed to our case, including the $\log P$ (logarithm of partition coefficient) value of the solvent, the accessibility of CALB and the miscibility of the intermediate and the final products in the solvent. The $\log P$ values of diphenyl ether and dodecane are higher than 1.9. They are more efficient for producing high molecular weight polyesters than diglyme. Furthermore, we found that CALB dispersed well in diphenyl ether and diglyme, but adhered tightly to the flasks in dodecane. Additionally, PBS with low molecular weight and PBSI are fully miscible in diphenyl ether at $80{ }^{\circ} \mathrm{C}$, but precipitated fast in diglyme and dodecane. Therefore, PBSI with higher $\mathrm{M}_{\mathrm{n}}$ is produced in 
diphenyl ether, since CALB is more accessible and the intermediate products are diffused better, which provide sufficient time and space for the chain growth and the transesterification of PBSI.

Moreover, we found that the enzymatic polymerizability of dimethyl itaconate was higher in diphenyl ether in comparison to the other two solvents. In addition, the molar composition of PBSI produced in diphenyl ether matched better with the feed composition of the monomers. The enzymatic polymerizability of dimethyl itaconate in dodecane and diglyme was quite low; only less than $6 \%$ of dimethyl itaconate was co-polymerized, although the reaction yield was considerably high. This is because PBS and PBSI are not soluble in dodecane and diglyme at $80{ }^{\circ} \mathrm{C}$. In diglyme and dodecane, 1,4-butanediol prefers to react with diethyl succinate first, since the enzyme polymerizability of diethyl succinate is higher than that of dimethyl itaconate. Low molecular weight PBS and PBSI composed with a little amount of itaconate was produced and precipitated fast from the reaction.

Therefore, diphenyl ether is the most suitable solvent for CALB-catalyzed synthesis of PBSI.

\subsubsection{Effect of Solvent Dosage on CALB-Catalyzed Co-Polymerization of Diethyl Succinate,}

Dimethyl Itaconate and 1,4-Butanediol

Figure 2 illustrates the values of product $M_{n}, X_{I}$ and reaction yield as a function of diphenyl ether dosage. PBSI with the highest values of $M_{n}, X_{I}$ and reaction yield was obtained from the reaction with $150 \mathrm{wt} \%$ of diphenyl ether (in relation to the total amount of monomers).

Figure 2. The effect of diphenyl ether dosage on CALB-catalyzed synthesis of PBSI.

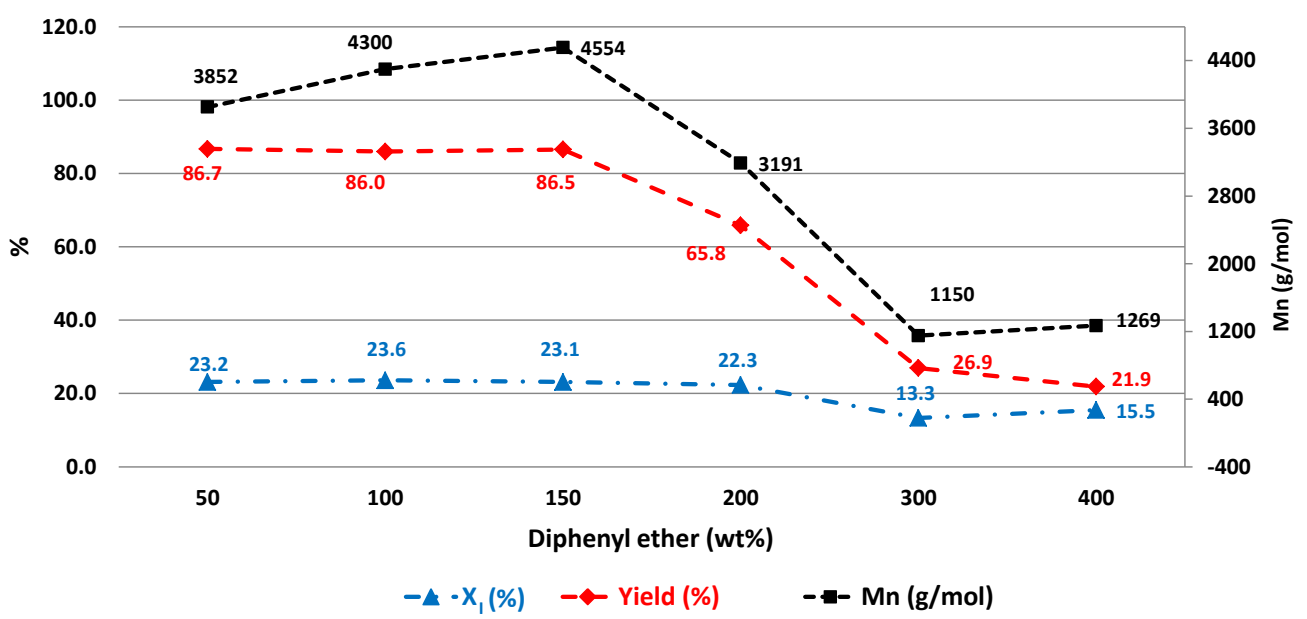

Polymerization conditions: 50\%-400 wt \% of diphenyl ether; $\mathrm{F}_{\mathrm{S}} / \mathrm{F}_{\mathrm{I}} / \mathrm{F}_{\mathrm{B}}=25 \% / 25 \% / 50 \%$; Stage-1: $80{ }^{\circ} \mathrm{C}, 2 \mathrm{~h}$, $\mathrm{N}_{2}$; Stage-2: $80{ }^{\circ} \mathrm{C}, 94 \mathrm{~h}$, vacuum $2 \mathrm{mmHg} ; \mathrm{M}_{\mathrm{n}}$ was calculated from ${ }^{1} \mathrm{H}-\mathrm{NMR}$ spectra.

As presented in Figure 2, the values of product $\mathrm{X}_{\mathrm{I}}$ and reaction yield remained almost the same, when the dosage of diphenyl ether was increased from $50 \%$ to $150 \%$. The product $X_{I}$ was around $23 \%$, and the reaction yield was close to $87 \%$. The corresponding $M_{n}$ increased from 3,852 $\mathrm{g} / \mathrm{mol}$ to $4,554 \mathrm{~g} / \mathrm{mol}$. The $\mathrm{X}_{\mathrm{I}}$ value calculated from ${ }^{1} \mathrm{H}-\mathrm{NMR}$ was in good agreement with the feed ratio of itaconate. The synchronous increase of product $\mathrm{M}_{\mathrm{n}}$ with the solvent dosage was due to the better diffusion of the reactants in dilute reaction.

By increasing the solvent dosage from $150 \%$ to $400 \%$, the values of product $M_{n}$ and reaction yield decreased significantly. The $\mathrm{M}_{\mathrm{n}}$ reduced from $4,554 \mathrm{~g} / \mathrm{mol}$ to $1,269 \mathrm{~g} / \mathrm{mol}$, while the reaction yield 
decreased from $86.5 \%$ to $21.9 \%$. As for the $\mathrm{X}_{\mathrm{I}}$ value, it remained similar, around $23 \%$, when the solvent dosage was increased to $200 \%$. On further dilution to $300 \%$, it dropped to $13.3 \%$, and on dilution to $400 \%$, it remained more or less the same: $14.6 \%$. We suspect that the increase of the residual alcohol amount and the decrease of the polymerization rate in dilute reaction could be the reasons. The alcohols were more difficult to remove by vacuum at a certain low concentration in dilute solution. The absolute amount of the residual alcohols was higher in the reactions with higher solvent dosage. At the same time, the polymerization rate was reduced, since the concentrations of CALB and the reactants were lower. The transesterification of oligomers with itaconate was hindered, and only low molecular weight co-polyesters were produced. The low molecular weight PBSI composed with a higher amount of itaconate is soluble in methanol. In this case, only PBSI with a lower amount of itaconate was obtained after purification, which led to the lower value of the reaction yield.

As a result, the best diphenyl ether dosage for in vitro synthesis of PBSI is $150 \mathrm{wt} \%$ (in relation to the total amount of monomers).

\subsubsection{Effect of Oligomerization Time during the First Stage on CALB-Catalyzed Co-Polymerization of Diethyl Succinate, Dimethyl Itaconate and 1,4-Butanediol}

As shown in Table 2, the selected oligomerization time has no obvious effects on the composition and the reaction yield of PBSI. PBSI with the highest $\mathrm{M}_{\mathrm{n}}$ was synthesized from the reaction conducting $2 \mathrm{~h}$ oligomerization during the first stage.

Table 2. The effect of oligomerization time on CALB-catalyzed synthesis of PBSI.

\begin{tabular}{ccccccccc}
\hline & \multicolumn{9}{c}{ Molar composition } & & \\
\cline { 2 - 6 } Oligomerization time & \multicolumn{6}{c}{ Feed (\%) } & \multicolumn{4}{c}{ PBSI $^{\mathbf{a}}(\boldsymbol{\%})$} & $\mathbf{F}_{\mathbf{I}}$ & $\mathbf{F}_{\mathbf{B}}$ & $\mathbf{X}_{\mathbf{S}}$ & $\mathbf{X}_{\mathbf{I}}$ & $\mathbf{X}_{\mathbf{B}}$ & $\mathbf{M}_{\mathbf{n}}(\mathbf{g} / \mathbf{m o l})$ & Yield (\%) \\
\hline $2 \mathrm{~h}$ & 35 & 15 & 50 & 35.7 & 14.1 & 50.2 & 3,936 & 87.7 \\
$6 \mathrm{~h}$ & 35 & 15 & 50 & 35.2 & 14.9 & 49.9 & 3,212 & 87.6 \\
$12 \mathrm{~h}$ & 35 & 15 & 50 & 36.3 & 14.4 & 49.3 & 2,960 & 84.1 \\
$2 \mathrm{~h}$ & 25 & 25 & 50 & 27.0 & 23.1 & 49.9 & 2,935 & 73.1 \\
$6 \mathrm{~h}$ & 25 & 25 & 50 & 28.9 & 21.5 & 49.6 & 2,459 & 68.5 \\
$12 \mathrm{~h}$ & 25 & 25 & 50 & 27.5 & 22.8 & 49.7 & 2,609 & 71.6 \\
\hline
\end{tabular}

Polymerization conditions: $150 \mathrm{wt} \%$ of diphenyl ether; Stage-1: $80{ }^{\circ} \mathrm{C}, 2-12 \mathrm{~h}, \mathrm{~N}_{2}$; Stage-2: $80{ }^{\circ} \mathrm{C}, 94 \mathrm{~h}$, vacuum $2 \mathrm{mmHg}$; ${ }^{\text {a }}$ molar composition determined by integration of the ${ }^{1} \mathrm{H}-\mathrm{NMR}$ spectra; ${ }^{\mathrm{b}}$ number average molecular weight calculated from ${ }^{1} \mathrm{H}-\mathrm{NMR}$ spectra.

When the feed ratio of dimethyl itaconate was $15 \%$, the composition of PBSI agreed well with the feed composition of the monomers, which was independent of the time of oligomerization. The reaction yield was quite satisfying (higher than $84 \%$ ). However, the product $\mathrm{M}_{n}$ decreased from $3,936 \mathrm{~g} / \mathrm{mol}$ to $2,960 \mathrm{~g} / \mathrm{mol}$, with increasing the oligomerization time from $2 \mathrm{~h}$ to $12 \mathrm{~h}$.

Similar trends were obtained when the feed ratio of dimethyl itaconate was $25 \%$. In spite of increasing the oligomerization time from $2 \mathrm{~h}, 6 \mathrm{~h}$ and up to $12 \mathrm{~h}$, the composition and reaction yield of PBSI remained almost the same. The product $\mathrm{M}_{\mathrm{n}}$, however, decreased a little from $2,935 \mathrm{~g} / \mathrm{mol}(2 \mathrm{~h}$ oligomerization) to $2,609 \mathrm{~g} / \mathrm{mol}$ (12 h oligomerization). 
The enzymatic oligomerization process of diethyl succinate, dimethyl itaconate and 1,4-butanediol was monitored by in situ ${ }^{1} \mathrm{H}-\mathrm{NMR}$, as shown in Figure 3. The ${ }^{1} \mathrm{H}-\mathrm{NMR}$ spectra of the intermediate products reacted for more than $30 \mathrm{~min}$ were almost identical, except the signals belonging to the active hydroxyl groups at 1.7-2.2 ppm. It is suspected that the monomers were fully transformed to oligomers after $30 \mathrm{~min}$ during the first stage.

Therefore, it can be concluded that $2 \mathrm{~h}$ of oligomerization during the first stage will be sufficient enough for CALB-catalyzed synthesis of PBSI.

Figure 3. In situ ${ }^{1} \mathrm{H}-\mathrm{NMR}$ investigation of the oligomerization process of: (a) diethyl succinate (35\%), dimethyl itaconate (15\%) and 1,4-butanediol (50\%); (b) diethyl succinate (25\%), dimethyl itaconate (25\%) and 1,4-butanediol (50\%).

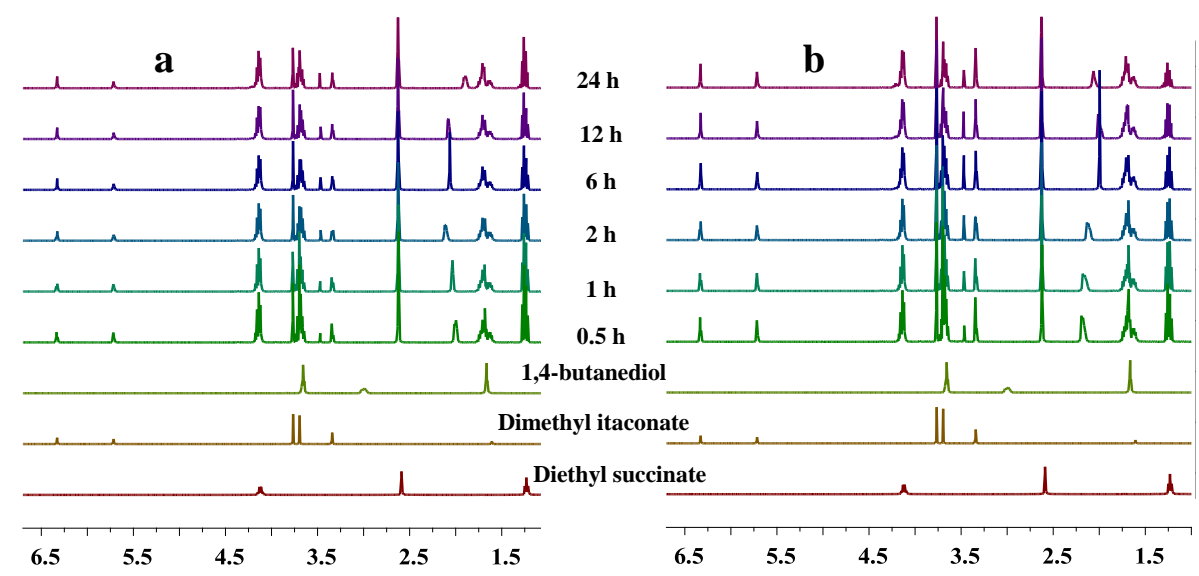

2.1.4. Effect of Vacuum during the Second Stage on CALB-Catalyzed Co-Polymerization of Diethyl Succinate, Dimethyl Itaconate and 1,4-Butanediol

As presented in Table 3, the vacuum during the second stage has a significant impact on the CALB-catalyzed co-polymerization. PBSI with the highest values of $X_{I}, M_{n}$ and reaction yield was produced by the co-polymerizations with the highest vacuum applied $(2 \mathrm{mmHg}$ ). Furthermore, the composition of PBSI produced under higher vacuum matched better with the feed composition of the monomers.

Table 3. The effect of vacuum on CALB-catalyzed synthesis of PBSI.

\begin{tabular}{ccccccccc}
\hline & \multicolumn{9}{c}{ Molar composition } & & \\
\cline { 2 - 7 } Vacuum & $\mathbf{F}_{\mathbf{S}}$ & $\mathbf{F}_{\mathbf{I}}$ & $\mathbf{F}_{\mathbf{B}}$ & $\mathbf{X}_{\mathbf{S}}$ & $\mathbf{X}_{\mathbf{I}}$ & $\mathbf{X}_{\mathbf{B}}$ & $\mathbf{M}_{\mathbf{n}}(\mathbf{g} / \mathbf{m o l})$ & Yield (\%) \\
\hline $2 \mathrm{mmHg}$ & 35 & 15 & 50 & 35.7 & 14.1 & 50.2 & 3,936 & 87.7 \\
$10-20 \mathrm{mmHg}$ & 35 & 15 & 50 & 37.1 & 13.1 & 49.8 & 2,552 & 56.2 \\
$40 \mathrm{mmHg}$ & 35 & 15 & 50 & 40.5 & 10.5 & 49.0 & 1,304 & 55.5 \\
$2 \mathrm{mmHg}$ & 25 & 25 & 50 & 27.0 & 23.1 & 49.9 & 2,935 & 73.1 \\
$10-20 \mathrm{mmHg}$ & 25 & 25 & 50 & 31.7 & 19.1 & 49.2 & 2,328 & 19.5 \\
$40 \mathrm{mmHg}$ & 25 & 25 & 50 & 35.2 & 15.9 & 48.9 & 1,203 & 22.6 \\
\hline
\end{tabular}

Polymerization conditions: $150 \mathrm{wt} \%$ of diphenyl ether; Stage-1: $80{ }^{\circ} \mathrm{C}, 2 \mathrm{~h}, \mathrm{~N}_{2}$; Stage-2: $80{ }^{\circ} \mathrm{C}, 94 \mathrm{~h}$, vacuum at $2-40 \mathrm{mmHg} ;{ }^{a}$ molar composition determined by integration of the ${ }^{1} \mathrm{H}-\mathrm{NMR}$ spectra; ${ }^{\mathrm{b}}$ number average molecular weight calculated from ${ }^{1} \mathrm{H}-\mathrm{NMR}$ spectra. 
When the feed ratio of dimethyl itaconate was $15 \%$, the values of product $\mathrm{X}_{\mathrm{I}}, \mathrm{M}_{\mathrm{n}}$ and reaction yield increased significantly with an increase of vacuum. The values of product $\mathrm{X}_{\mathrm{I}}$ from the reactions under vacuum of $40 \mathrm{mmHg}, 10-20 \mathrm{mmHg}$ and $2 \mathrm{mmHg}$ were $10.5 \%, 13.1 \%$ and $14.1 \%$, respectively. The corresponding product $\mathrm{M}_{\mathrm{n}}$ was 1,304 $\mathrm{g} / \mathrm{mol}, 2,552 \mathrm{~g} / \mathrm{mol}$ and 3,936 $\mathrm{g} / \mathrm{mol}$. The reaction yield was $55.5 \%, 56.2 \%$ and $87.7 \%$, respectively.

The same trend of product $\mathrm{X}_{\mathrm{I}}, \mathrm{M}_{\mathrm{n}}$ and reaction yield as a function of vacuum was identified, when the feed ratio of dimethyl itaconate was $25 \%$. By lowering the pressure from $40 \mathrm{mmHg}$ to $2 \mathrm{mmHg}$, the values of product $X_{I}$ increased from $15.9 \%$ to $23.1 \%$. The product $M_{n}$ increased from $1,203 \mathrm{~g} / \mathrm{mol}$ to $2,935 \mathrm{~g} / \mathrm{mol}$. Additionally, the reaction yield increased from $22.6 \%$ to $73.1 \%$.

The effect of vacuum is quite reasonable, since the residual alcohols and water can be further eliminated from the reaction under higher vacuum, which facilitates the chain growth of co-polyesters. It is obvious that the reduced pressure shall be regulated to $2 \mathrm{mmHg}$ during the second stage for in vitro synthesis of PBSI in diphenyl ether.

\subsection{Effect of Itaconate Structure on CALB-Catalyzed Synthesis of PBSI in Diphenyl Ether}

Four itaconate derivatives were studied, namely itaconic acid, dimethyl itaconate, diethyl itaconate and dibutyl itaconate. The byproducts generated during polycondensation are water, methanol, ethanol and n-butyl alcohol, respectively.

Phase separation of itaconic acid in the presence of the other reactants was observed. This is due to the fact that itaconic acid has a rather low solubility in the mixture of diphenyl ether, diethyl succinate and 1,4-butanediol.

Dimethyl itaconate dissolved in the reaction medium when at temperatures above $60{ }^{\circ} \mathrm{C}$. The co-polymerization with dimethyl itaconate, diethyl itaconate or dibutyl itaconate was homogeneous.

PBSI could not be obtained in a sufficient amount when using itaconic acid as the unsaturated monomer. The reaction yield was extremely low, less than 4\%, as shown in Figure 4a.

Figure 4. The effect of itaconate structure on CALB-catalyzed synthesis of PBSI: (a) the reaction yield of PBSI as a function of the feed ratio of itaconate; (b) the mole percentage of itaconate in PBSI $\left(\mathrm{X}_{\mathrm{I}}\right)$ as a function of the feed ratio of itaconate.
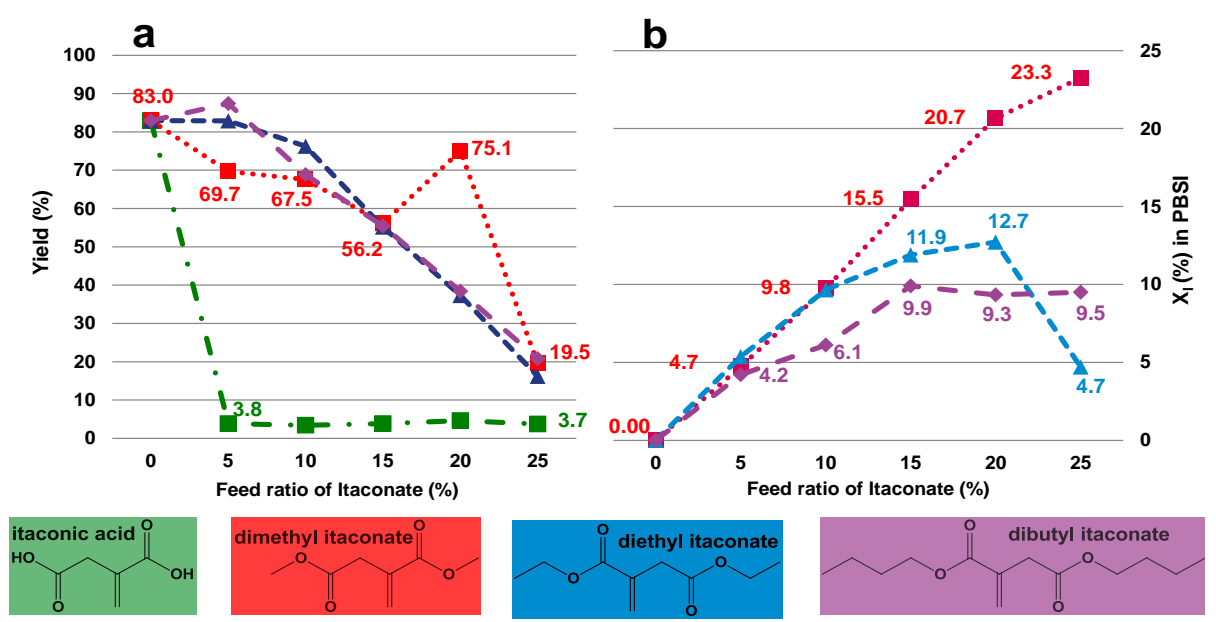

Polymerization conditions: $150 \mathrm{wt} \%$ of diphenyl ether; Stage-1: $80^{\circ} \mathrm{C}, 2 \mathrm{~h}, \mathrm{~N}_{2}$; Stage-2: $80{ }^{\circ} \mathrm{C}, 94 \mathrm{~h}$, vacuum $10-20 \mathrm{mmHg}$. 
For the co-polymerizations with dialkyl itaconate esters, the reaction yield of PBSI decreased with increasing the feed ratio of itaconate, as displayed in Figure 4a, e.g., the reaction yield decreased from $83.0 \%$ to $19.5 \%$ when the feed ratio of dimethyl itaconate increased from $0 \%$ to $25 \%$. The same trend of the reaction yield as a function of the feed ratio of itaconate was also observed in other co-polymerizations with diethyl itaconate or dibutyl itaconate.

Moreover, for reactions with dimethyl itaconate, the value of product $X_{I}$ was in good accordance with the corresponding feed ratio of itaconate, as presented in Figure $4 \mathrm{~b}$. While the feed ratio of itaconate was $0 \%, 5 \%, 10 \%, 15 \%, 20 \%$ and $25 \%$, the value of product $\mathrm{X}_{\mathrm{I}}$ was $0.0 \%, 4.7 \%, 9.8 \%$, $15.5 \%, 20.7 \%$ and $23.3 \%$, respectively. The deviation between the $\mathrm{X}_{\mathrm{I}}$ value calculated from ${ }^{1} \mathrm{H}-\mathrm{NMR}$ spectra and the corresponding feed ratio of itaconate was quite small.

However, for co-polymerizations with diethyl itaconate, the value of product $\mathrm{X}_{\mathrm{I}}$ deviated obviously from the corresponding feed ratio of itaconate, especially when the feed ratio of diethyl itaconate was higher than $10 \%$. While the feed ratio of diethyl itaconate was $0 \%, 5 \%, 10 \%, 15 \%, 20 \%$ and $25 \%$, the corresponding product $\mathrm{X}_{\mathrm{I}}$ was $0.0 \%, 5.4 \%, 9.7 \%, 11.9 \%, 12.7 \%$ and $4.7 \%$, respectively. The value of product $\mathrm{X}_{\mathrm{I}}$ only matched with the feed ratio of diethyl itaconate when less than or equal to $10 \%$ of diethyl itaconate was added. The highest $\mathrm{X}_{\mathrm{I}}$ value was only $12.7 \%$, which was produced from the reaction with $20 \%$ of diethyl itaconate.

For co-polymerizations with dibutyl itaconate, the highest $\mathrm{X}_{\mathrm{I}}$ value achieved was only $9.9 \%$. The value of product $\mathrm{X}_{\mathrm{I}}$ increased from $0.0 \%$ to $9.9 \%$ as the corresponding feed ratio of dibutyl itaconate ascended from $0 \%$ to $15 \%$. A plateau value was reached of around $10 \%$ when the feed ratio of dibutyl itaconate was further increased from $15 \%$ to $25 \%$.

As a result, the enzyme polymerizability sequence of itaconate derivatives in diphenyl ether is dimethyl itaconate, diethyl itaconate, dibutyl itaconate and itaconic acid, from high to low. Itaconic acid is not favored by CALB, since it is immiscible in solution, which makes it inaccessible to the biocatalyst. Dimethyl itaconate is the most polymerizable derivative by CALB, since the reaction byproduct, methanol, can be removed easily under vacuum, because of the low boiling temperature of $64.7{ }^{\circ} \mathrm{C}$, compared with ethanol $\left(\mathrm{bp}=78.4^{\circ} \mathrm{C}\right)$ and n-butyl alcohol $\left(\mathrm{bp}=117.7^{\circ} \mathrm{C}\right)$. Besides, the chemical reactivity of the alkyl esters is another reason. It is well known that methyl esters are chemically much more reactive than ethyl and butyl esters.

Therefore, dimethyl itaconate is the most preferred unsaturated monomer for in vitro synthesis of PBSI in diphenyl ether.

In conclusion, combining the results from Sections 2.1 to 2.2, we have established the optimal polymerization conditions for CALB-catalyzed co-polymerization of diethyl succinate, itaconate and 1,4-butanediol, which are as follows:

(1) using diphenyl ether as solvent;

(2) the dosage of diphenyl ether is $150 \mathrm{wt} \%$ (in relation to the total amount of monomers);

(3) oligomerization for $2 \mathrm{~h}$ during the first stage;

(4) regulating vacuum to $2 \mathrm{mmHg}$ during the second stage;

(5) applying dimethyl itaconate as the unsaturated monomer. 


\subsection{CALB-Catalyzed Synthesis of PBSI Using Optimal Polymerization Conditions}

Diethyl succinate, dimethyl itaconate and 1,4-butanediol were co-polymerized in the presence of CALB, using the optimal conditions we established. A series of co-polyesters was produced by alternating the feed ratio of dimethyl itaconate from $0 \%$ to $30 \%$. No products were obtained if the feed ratio of dimethyl itaconate was increased to $35 \%$ and $50 \%$. For the two control reactions without CALB, also no polymers were obtained after purification. The molar composition, reaction yield, molecular weight and the thermal properties of PBS and PBSI are summarized in Table 4.

As shown in Table 4 and plotted in Figure 5a, co-polyesters with tunable compositions and satisfying reaction yields were achieved, by adjusting the feed ratio of dimethyl itaconate from $0 \%$ to $25 \%$. The mole percentage of itaconate in PBSI can be controlled from $0 \%$ to $23.5 \%$. The corresponding reaction yield was quite good, higher than $75 \%$.

Table 4. Summary of the results for the CALB-catalyzed synthesis of PBS and PBSI.

\begin{tabular}{|c|c|c|c|c|c|c|c|c|c|c|c|c|c|c|}
\hline \multirow[b]{3}{*}{ Co-polyester } & \multicolumn{6}{|c|}{ Molar composition } & \multirow[b]{3}{*}{$\begin{array}{c}\text { Yield } \\
(\%) \\
\end{array}$} & \multirow[b]{3}{*}{$\begin{array}{c}\mathbf{T}_{\mathbf{g}}^{\mathbf{b}} \\
\left({ }^{\circ} \mathbf{C}\right)\end{array}$} & \multirow[b]{3}{*}{$\begin{array}{l}\mathbf{T}_{\mathbf{m}}{ }^{\mathbf{c}} \\
\left({ }^{\circ} \mathbf{C}\right) \\
\end{array}$} & \multirow[b]{3}{*}{$\begin{array}{c}\mathbf{T}_{\mathbf{d}}{ }^{\mathbf{d}} \\
\left({ }^{\circ} \mathbf{C}\right) \\
\end{array}$} & \multicolumn{4}{|c|}{ Molecular Weight } \\
\hline & \multicolumn{3}{|c|}{ Feed $(\%)$} & \multicolumn{3}{|c|}{ PBSI $^{a}(\%)$} & & & & & \multirow{2}{*}{$\begin{array}{c}\text { NMR } \\
M_{n}{ }^{e}\end{array}$} & \multirow{2}{*}{\multicolumn{2}{|c|}{$\begin{array}{cc} & \text { GPC } \\
M_{n} & M_{w}\end{array}$}} & \multirow[b]{2}{*}{$\mathbf{M}_{\mathrm{w}} / \mathbf{M}_{\mathrm{r}}$} \\
\hline & $\mathbf{F}_{\mathbf{S}}$ & $\mathbf{F}_{\mathbf{I}}$ & $\mathbf{F}_{\mathbf{B}}$ & $\mathbf{X}_{\mathbf{S}}$ & $\mathbf{X}_{\mathbf{I}}$ & $\mathbf{X}_{\mathbf{B}}$ & & & & & & & & \\
\hline PBS & 50 & 0 & 50 & 50.5 & 0.0 & 49.5 & 85.7 & -35.9 & 112.9 & 406.1 & 4,463 & 6,017 & 11,520 & 1.91 \\
\hline $\mathrm{PB}_{50} \mathrm{~S}_{40} \mathrm{I}_{10}$ & 40 & 10 & 50 & 39.7 & 10.4 & 49.9 & 84.6 & -38.8 & 94.6 & 402.0 & 4,696 & 10,128 & 19,236 & 1.90 \\
\hline $\mathrm{PB}_{50} \mathrm{~S}_{35} \mathrm{I}_{15}$ & 35 & 15 & 50 & 35.0 & 15.7 & 49.3 & 90.0 & -36.7 & 80.3 & 410.9 & 6,494 & 13,288 & 22,642 & 1.70 \\
\hline $\mathrm{PB}_{50} \mathrm{~S}_{30} \mathrm{I}_{20}$ & 30 & 20 & 50 & 30.9 & 20.1 & 49.0 & 75.1 & -37.5 & 71.2 & 404.7 & 5,670 & 8,394 & 11,892 & 1.42 \\
\hline $\mathrm{PB}_{50} \mathrm{~S}_{25} \mathrm{I}_{25}$ & 25 & 25 & 50 & 27.2 & 23.5 & 49.3 & 86.5 & -38.4 & 57.4 & 407.9 & 4,554 & 11,096 & 16,587 & 1.49 \\
\hline PBSI & 20 & 30 & 50 & 36.4 & 15.6 & 48.0 & 20.9 & -49.6 & 69.8 & 396.9 & 1,004 & 1,948 & 2,203 & 1.13 \\
\hline $\mathrm{NA}^{\mathrm{f}}$ & 15 & 35 & 50 & - & - & - & - & - & - & - & - & - & - & - \\
\hline $\mathrm{NA}^{\mathrm{f}}$ & 0 & 50 & 50 & - & - & - & - & - & - & - & - & - & - & - \\
\hline Control-1 ${ }^{\mathrm{g}}$ & 50 & 0 & 50 & - & - & - & - & - & - & - & - & - & - & - \\
\hline Control-2 ${ }^{\mathrm{g}}$ & 25 & 25 & 50 & - & - & - & - & - & - & - & - & - & - & - \\
\hline
\end{tabular}

${ }^{a}$ Molar composition determined by integration of the ${ }^{1} \mathrm{H}-\mathrm{NMR}$ spectra; ${ }^{\mathrm{b}}$ glass-transition temperature $\left(\mathrm{T}_{\mathrm{g}}\right)$ from differential scanning calorimetry (DSC) by a quench method; ${ }^{c}$ melting temperature $\left(\mathrm{T}_{\mathrm{m}}\right)$ from DSC measurements, first scan; ${ }^{d}$ the temperature of the maximal rate of decomposition $\left(\mathrm{T}_{\mathrm{d}}\right)$ from thermal gravimetric analysis (TGA) measurement; ${ }^{\mathrm{e}}$ number average molecular weight calculated from ${ }^{1} \mathrm{H}-\mathrm{NMR}$ spectra; ${ }^{\mathrm{f}}$ no polymer was obtained after precipitation; ${ }^{\mathrm{g}}$ control reactions without CALB. No polymer was obtained after precipitation.

The carbon-carbon double bonds were well preserved in the unsaturated co-polyesters, as confirmed by ${ }^{1} \mathrm{H}-\mathrm{NMR}$ spectra in Figure 6 . No resonances can be assigned to the deterioration of carbon-carbon double bonds. As displayed in the ${ }^{1} \mathrm{H}-\mathrm{NMR}$ spectra of $\mathrm{PB}_{50} \mathrm{~S}_{35} \mathrm{I}_{15}$ and $\mathrm{PB}_{50} \mathrm{~S}_{25} \mathrm{I}_{25}$, the ratio between the integration values of the two separated peaks assigned to the protons of the carbon-carbon double bonds (6.32 ppm and $5.72 \mathrm{ppm}$, respectively) and the peak assigned to the protons of the methylene group of itaconate $(3.33 \mathrm{ppm})$ was close to $1: 1: 2$, which was exactly the same as that of dimethyl itaconate. Besides, the final products were white semicrystalline powders without discoloration. It is clear that no side reaction occurred during the enzymatic co-polymerizations. 
Figure 5. (a) The mole percentage of itaconate $\left(\mathrm{X}_{\mathrm{I}}\right)$ and the reaction yield of PBSI as a function of the feed ratio of dimethyl itaconate $\left(\mathrm{F}_{\mathrm{I}}\right)$; (b) Overlay of gel permeation chromatography (GPC) elution curves in chloroform; PBSI was synthesized via the optimal conditions.
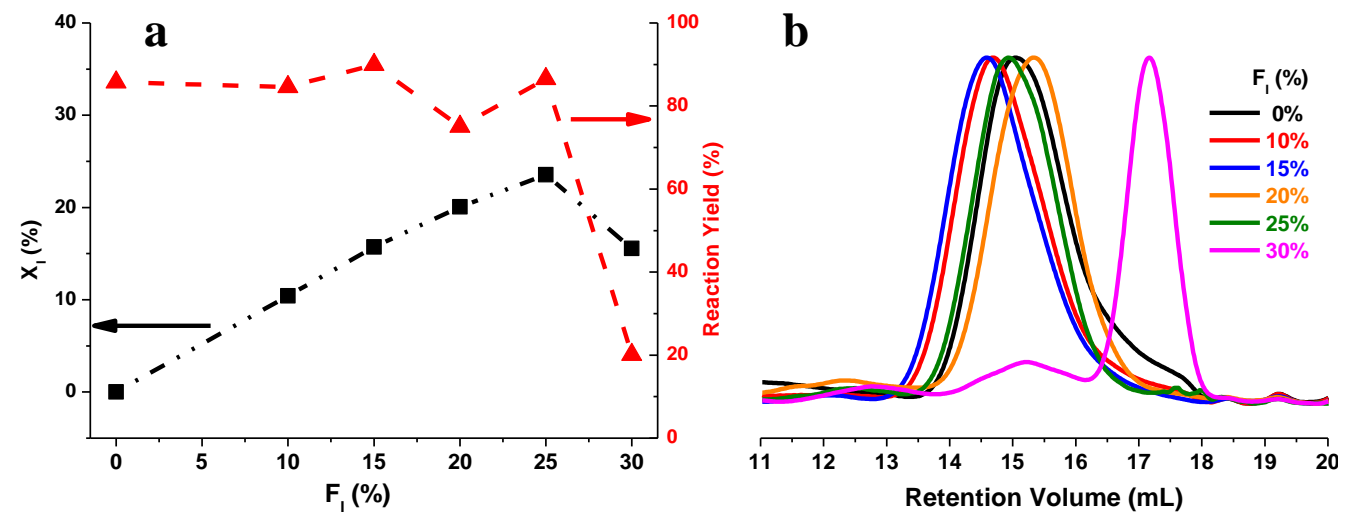

Figure 6. ${ }^{1} \mathrm{H}-\mathrm{NMR}$ spectra of dimethyl itaconate, $\mathrm{PB}_{50} \mathrm{~S}_{35} \mathrm{I}_{15}$ and $\mathrm{PB}_{50} \mathrm{~S}_{25} \mathrm{I}_{25}$ in $\mathrm{CDCl}_{3}$.

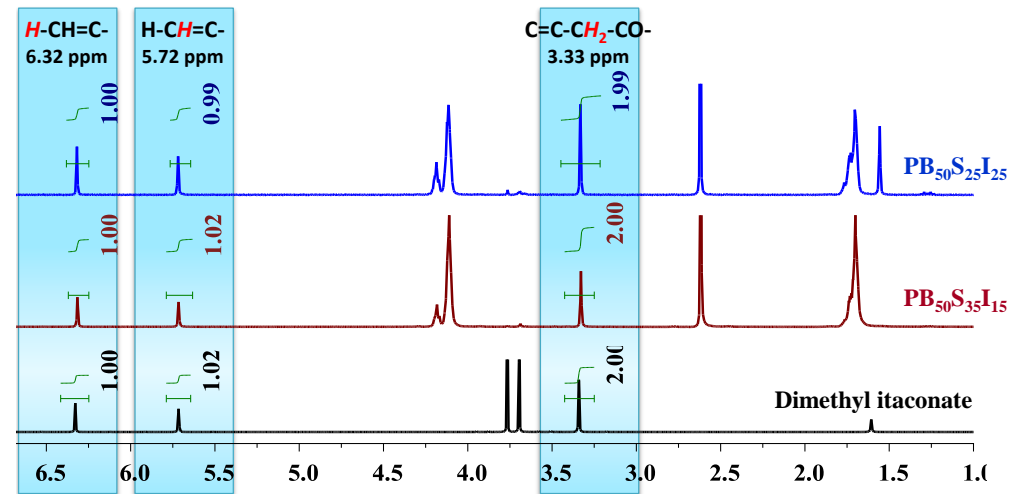

The product $\mathrm{M}_{\mathrm{n}}$ calculated from ${ }^{1} \mathrm{H}-\mathrm{NMR}$ was around 4,000-6,500 $\mathrm{g} / \mathrm{mol}$, while the feed ratio of dimethyl itaconate was less than or equal to $25 \%$. GPC results indicate that the corresponding $\mathrm{M}_{\mathrm{n}}$ was around 6,000-14,000 g/mol. The polydispersity index (PDI, $M_{w} / M_{n}$ ) was between 1.42 and 1.91. The molecular weight of the saturated polyesters was lower than that of the unsaturated counterparts, and the PDI was higher. This is due to the higher melting temperature of PBS, which is around $112{ }^{\circ} \mathrm{C}$. During the polycondensation step, the reaction with PBS solidified after $19 \mathrm{~h}$ at $80{ }^{\circ} \mathrm{C}$. The chain growth and transesterification of PBS stopped in the solid state. In contrast to this, the reaction with PBSI proceeded continuously in the liquid state.

The highest value of $X_{I}$ achieved in PBSI was $23.5 \%$, from the reaction with $25 \%$ of dimethyl itaconate. If the feed ratio of dimethyl itaconate was increased to $30 \%$, the product $\mathrm{X}_{\mathrm{I}}$ reduced to $15.6 \%$. The corresponding product $\mathrm{M}_{\mathrm{n}}$ and the reaction yield decreased significantly to $1,948 \mathrm{~g} / \mathrm{mol}$ and $20.9 \%$, as shown in Figure 5a. If the feed ratio of dimethyl itaconate was further increased to $35 \%$ and $50 \%$, no polymer was obtained after precipitation in cold methanol.

As shown in Figure 5b, PBSI synthesized from the reaction with $30 \%$ of dimethyl itaconate had two peaks. The first peak was at a retention volume between 13.6 to $16.2 \mathrm{~mL}$, similar to that of the co-polyesters with high molecular weight; however, the concentration was much lower. The major peak was at a retention volume between 16.2 to $18.2 \mathrm{~mL}$, which means that the molecular weight of 
the most PBSI produced was quite low. It is clear that co-polyesters with two different molecular weight distributions were produced from reaction with $30 \%$ of dimethyl itaconate.

The limited incorporation of itaconate in PBSI could be attributed to the relatively low enzyme polymerizability of dimethyl itaconate compared to diethyl succinate. As shown in Figure 7, there are six possible microstructures in PBSI. It is easier for CALB to produce the microstructure of succinate-butylene-succinate (S-B-S) than that of succinate-butylene-itaconate (S-B-I) and itaconate-butylene-itaconate (I-B-I). The formation sequence from easy to difficult is S-B-S, S-B-I-1, S-B-I-2, I-B-I-1, I-B-I-2 and I-B-I-3. While the feed ratio of itaconate is $25 \%$, the molar ratio between succinate, itaconate and 1,4-butanediol is 1:1:2. The possible dominant microstructures in PBSI could be $-(\mathrm{S}-\mathrm{B}-\mathrm{I}-\mathrm{B})_{\mathrm{n}^{-}}$. If the feed ratio of itaconate is higher than $25 \%$, the possible structures could be -I-B-(S-B-I-B) $)_{n}-I-B-$, while some extra I-B-I structures are formed. However, the formation of the I-B-I microstructure is quite difficulty. Oligomers with itaconate ends will be terminated in chain growth, and the transesterification of oligomers with I-B-I structures will be hindered. Consequently, the molecular weight of PBSI will be lower. Low molecular weight PBSI is soluble in methanol and will be washed away during the purification steps. This is why we obtain only PBSI with the highest mole percentage of itaconate around $25 \%$.

This hypothesis also explains well why PBSI obtained from the reaction with $30 \%$ of dimethyl itaconate had lower values for $\mathrm{M}_{\mathrm{n}}$, mole percentage of itaconate and reaction yield, as well as, had two retention volume peaks, as plotted in Figure 5.

Figure 7. Possible types of microstructures in PBSI, the formation sequence from easy to difficult: S-B-S < S-B-I-1 < S-B-I-2 < I-B-I-1 < I-B-I-2 < I-B-I-3.

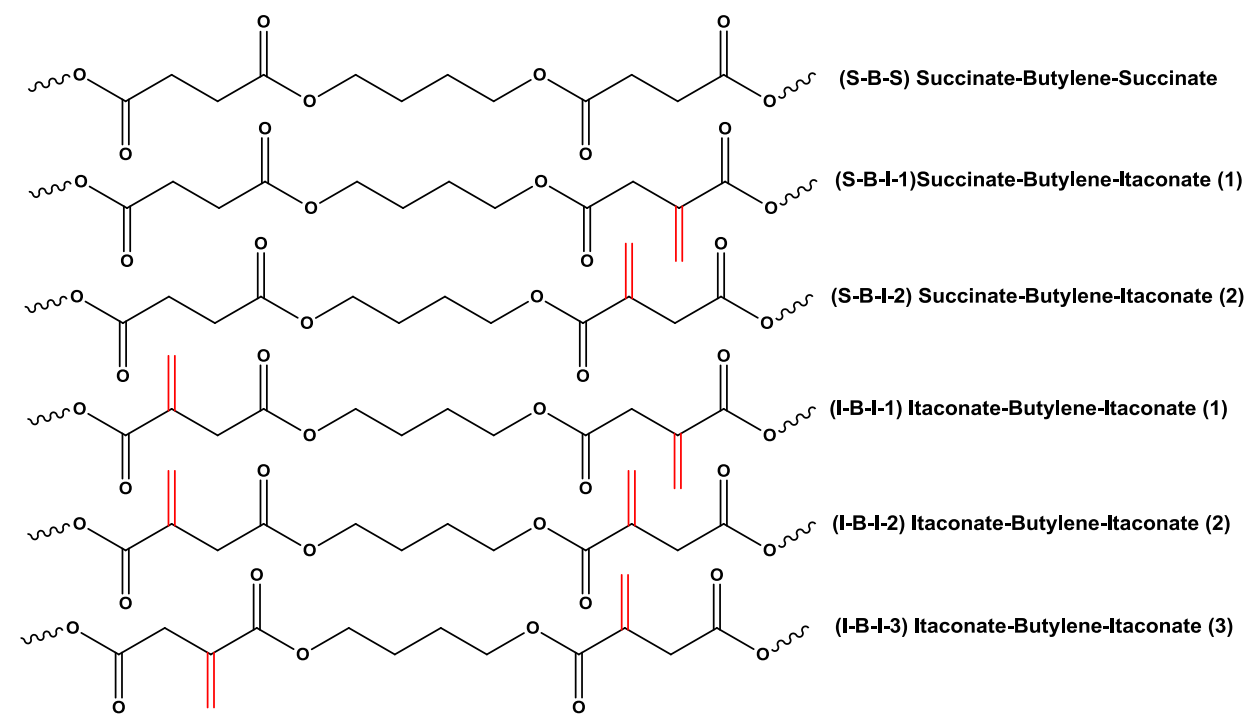

\subsection{Thermal Properties of PBS and PBSI}

The glass transition temperature $\left(\mathrm{T}_{\mathrm{g}}\right)$, the melting temperature $\left(\mathrm{T}_{\mathrm{m}}\right)$ and the temperature of the maximal rate of decomposition $\left(\mathrm{T}_{\mathrm{d}}\right)$ of PBS and PBSI are plotted as a function of the mole percentage of itaconate in Figure 8. We found that the amount of itaconate composed in the co-polyesters has no obvious effects on the $T_{g}$ and the thermal stability of PBSI. The $T_{g}$ and $T_{d}$ of PBS and PBSI were similar, as shown in Figure $8 \mathrm{a}$. The $\mathrm{T}_{\mathrm{g}}$ of the saturated PBS was $-35.9^{\circ} \mathrm{C}$. It was slightly higher than that 
of the rest of the unsaturated PBSI, which was around $-36--38{ }^{\circ} \mathrm{C}$. The $\mathrm{T}_{\mathrm{d}}$ of all polyesters was around $400{ }^{\circ} \mathrm{C}$.

However, the $\mathrm{T}_{\mathrm{m}}$ of the co-polyesters is significantly affected by the amount of itaconate composed in PBSI. The $\mathrm{T}_{\mathrm{m}}$ of the saturated PBS was $112.9{ }^{\circ} \mathrm{C}$, which was $55.5{ }^{\circ} \mathrm{C}$ higher than that of the unsaturated counterpart with $23.5 \%$ of itaconate. The $\mathrm{T}_{\mathrm{m}}$ of PBSI decreased almost linearly as a function of the mole percentage of itaconate, as shown in Figure $8 \mathrm{~b}$.

Figure 8. (a) the $T_{g}$ and $T_{d}$ of PBSI as a function of the mole percentage of itaconate $\left(X_{I}\right)$; (b) the $\mathrm{T}_{\mathrm{m}}$ of PBSI as a function of the mole percentage of itaconate $\left(\mathrm{X}_{\mathrm{I}}\right)$; PBSI was synthesized via the optimal conditions.
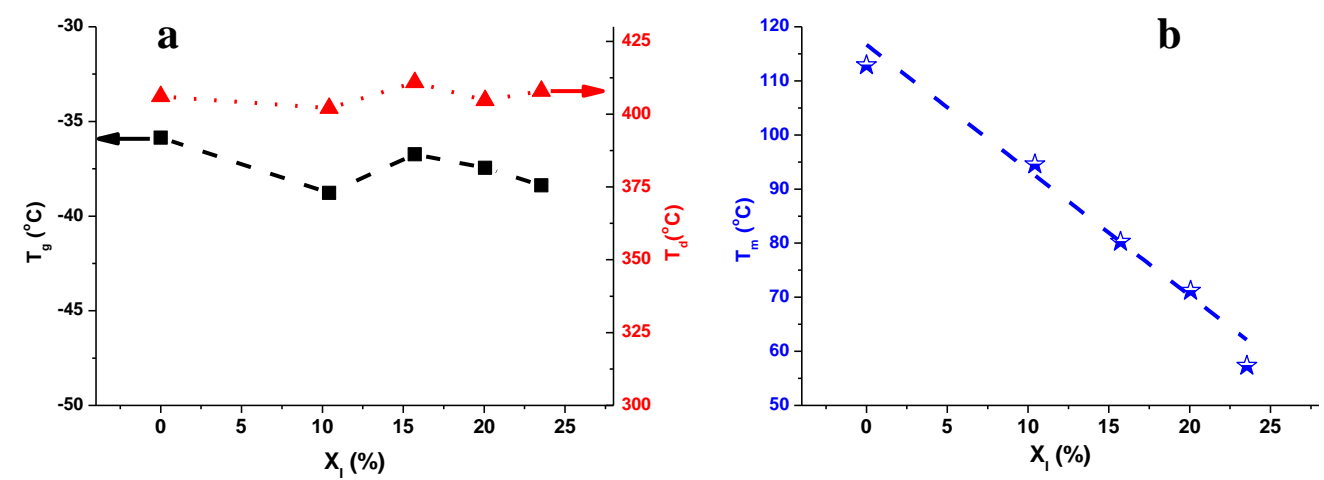

\section{Experimental}

\subsection{Materials}

Lipase acrylic resin from Candida antarctica Lipase B (CALB, in immobilized form as Novozyme $\left.{ }^{\circledR} 435,5,000+\mathrm{U} / \mathrm{g}\right)$, diethyl succinate $(99 \%)$, itaconic acid $(99 \%+)$, dimethyl itaconate (99\%), 1,4-butanediol (99\%+), dodecane (99\%+, anhydrous), diethylene glycol dimethyl ether (99.5\%, anhydrous) and diphenyl ether (99\%) were purchased from Aldrich. Diethyl itaconate (98\%+) and dibutyl itaconate $(95 \%+)$ were purchased from TCI EUROPE. Diphenyl ether was vacuum distilled and stored with $4 \AA$ molecular sieves before use. The other chemicals were used as received.

\subsection{General Procedure for CALB-Catalyzed Co-Polymerization of Succinate, Itaconate and}

\section{1,4-Butanediol in Solution}

CALB (10 wt\% in relation to the total amount of monomers, for all reactions) was first fed into a $25 \mathrm{~mL}$ flask and stored in a desiccator with phosphorus pentoxide at room temperature under high vacuum for $16 \mathrm{~h}$. Then diethyl succinate $(5.55 \mathrm{mmol})$, itaconate $(5.55 \mathrm{mmol}), 1,4$-butanediol $(11.10 \mathrm{mmol})$ and the solvent (usually $150 \mathrm{wt} \%$ in relation to the total amount of monomers) were added. With the protection of nitrogen, the monomers were oligomerized at $80{ }^{\circ} \mathrm{C}$ for $2-24 \mathrm{~h}$ under atmospheric pressure during the first stage. The oligomers were further polymerized for another $94 \mathrm{~h}$ at the same temperature under the reduced pressure of $2-40 \mathrm{mmHg}$ during the second stage.

After polymerization, chloroform $(25 \mathrm{~mL})$ was added into the reaction flask. CALB was filtered out and washed with chloroform $(35 \mathrm{~mL})$ three times. The collected solution was condensed by rotary evaporation at $40{ }^{\circ} \mathrm{C}$ under a vacuum of 300 mbar. The products were precipitated in cold methanol 
$\left(-20{ }^{\circ} \mathrm{C}\right)$ and washed with methanol three times. Finally, the polyesters were dried in a vacuum oven at $40{ }^{\circ} \mathrm{C}$ for $2-3$ days before analysis. The final polymers obtained were white semicrystalline powders.

${ }^{1} \mathrm{H}-\mathrm{NMR}\left(400 \mathrm{MHz}, \mathrm{CDCl}_{3}, \mathrm{ppm}\right)$ analysis of PBS and PBSI: 6.25-6.35 (1H, s, $\boldsymbol{H}$-CH=C-CO-, from itaconate), 5.65-5.75 $(1 \mathrm{H}, \mathrm{s}, \mathrm{H}-\mathrm{CH}=\mathrm{C}-\mathrm{CO}-$, from itaconate $), 4.05-4.25\left(4 \mathrm{H}, \mathrm{m},-\mathrm{CO}-\mathrm{O}-\mathrm{CH}_{2^{-}}\right.$, from 1,4-butanediol), 3.30-3.40 (2H, s, -C=C-CH${ }_{2}-\mathrm{CO}-$, from itaconate), 2.58-2.68 (4H, s, -OC-CH $2_{2}^{-}$, from succinate), 1.60-1.78 (4H, m, - $\mathrm{O}-\mathrm{CH}_{2}-\mathrm{CH}_{2}-\mathrm{CH}_{2}-\mathrm{CH}_{2}-\mathrm{O}-$, from 1,4-butanediol); low intensity signals due to end group-groups were observed at 3.75-3.79 $\left(3 \mathrm{H}, \mathrm{s},-\mathrm{O}-\mathrm{CH}_{3}\right.$, from itaconate), 3.63-3.73 (2H, m, $-\mathrm{CH}_{2}-\mathrm{OH}$, from 1,4-butanediol) and $1.15-1.32\left(3 \mathrm{H}, \mathrm{m},-\mathrm{OCH}_{2} \mathrm{CH}_{3}\right.$, from succinate). The spectra are shown in Figure 9a.

${ }^{13} \mathrm{C}-\mathrm{NMR}\left(100 \mathrm{MHz}, \mathrm{CDCl}_{3}, \mathrm{ppm}\right)$ analysis of PBS and PBSI: 172.2 (-CO-, from succinate), 170.6 (-CO-, from itaconate), 166.0 (-C=C-CO-O-, from itaconate), 133.8 ( $-\boldsymbol{C}=\mathrm{C}$-, from itaconate), 128.4 ( $-\mathrm{C}=\boldsymbol{C}$-, from itaconate), 62.5-65.0 (-CO- $\mathrm{CH}_{2^{-}}$, from 1,4-butanediol), 37.6 ( $\mathrm{CH}_{2^{-}}$, from itaconate), 29.0 ( $-\mathrm{CH}_{2^{-}}$, from succinate), $25.2\left(-\mathrm{CH}_{2^{-}}\right.$, from 1,4-butanediol); low intensity signals assigned to end-groups were determined at $62.2\left(-\mathrm{CH}_{2^{-}}\right.$, from 1,4-butanediol) and $51.8\left(-\mathrm{CH}_{3}\right.$, from itaconate). The spectra are shown in Figure 9b.

Figure 9. (a) ${ }^{1} \mathrm{H}-$; (b) ${ }^{13} \mathrm{C}-\mathrm{NMR}$ spectra of PBS and PBSI.

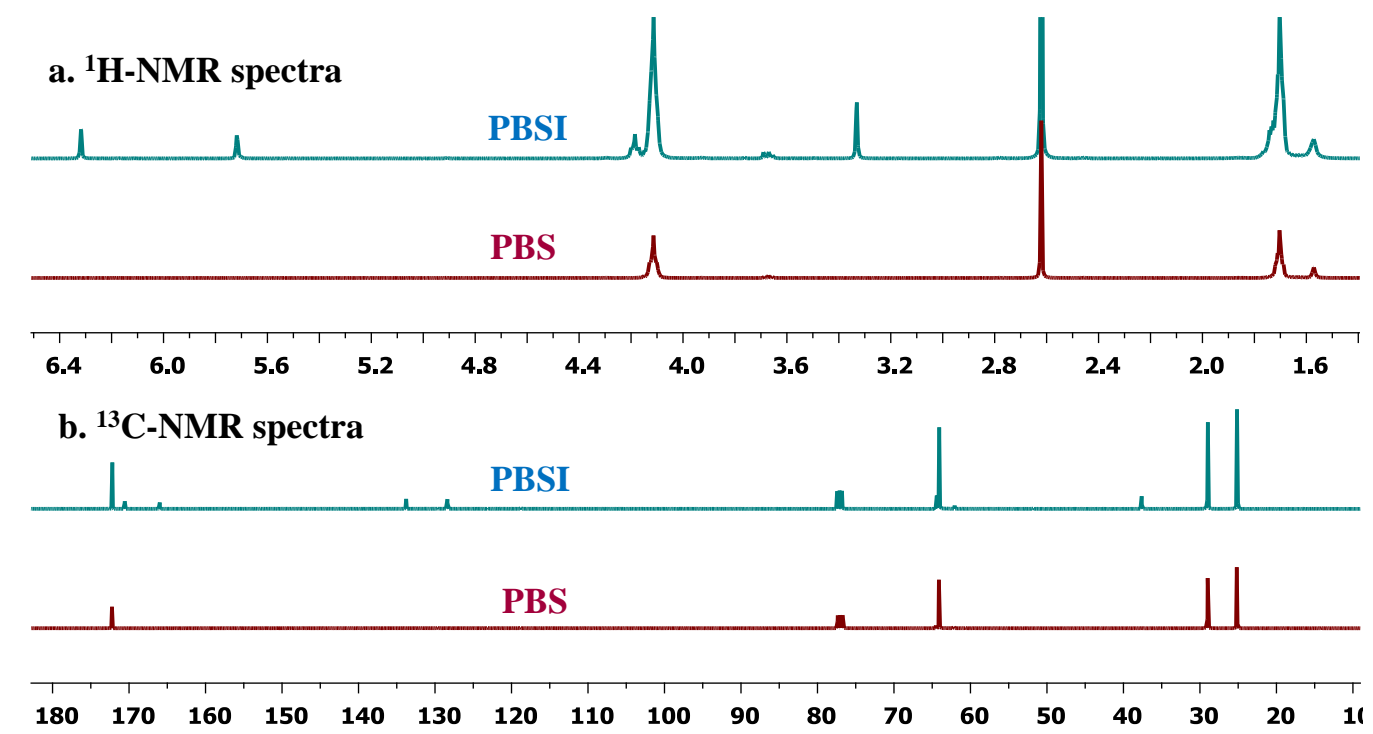

\subsection{Control Reactions for Enzymatic Polymerization}

Diethyl succinate, dimethyl itaconate and 1,4-butanediol were co-polymerized without CALB using the same method as we established. No polymer was obtained after precipitation.

\subsection{In situ ${ }^{1} H$-NMR Investigation of the Oligomerization Process of Diethyl Succinate, Dimethyl Itaconate and 1,4-Butanediol in Diphenyl Ether}

CALB (10 wt $\%$ in relation to the total amount of monomers) was pre-dried according to the general procedure described in Section 3.2. Diphenyl ether (150 wt\% in relation to the total amount of monomers) was used in this study. Diethyl succinate, dimethyl itaconate and 1,4-butanediol were enzymatically oligomerized at $80{ }^{\circ} \mathrm{C}$ under atmospheric pressure with the protection of nitrogen for $24 \mathrm{~h}$. 
At pre-selected time intervals, about $20 \mathrm{mg}$ of the solution was withdrawn from the reaction. They were added directly into a NMR tube containing $1 \mathrm{~g}$ of $\mathrm{CDCl}_{3}$ for ${ }^{1} \mathrm{H}-\mathrm{NMR}$ analysis.

\subsection{Instrumental Methods}

${ }^{1} \mathrm{H}$ - and ${ }^{13} \mathrm{C}-\mathrm{NMR}$ spectra of PBS and PBSI were characterized on a Varian VXR spectrometer (400 MHz for ${ }^{1} \mathrm{H}-\mathrm{NMR}$ analysis and $100 \mathrm{MHz}$ for ${ }^{13} \mathrm{C}-\mathrm{NMR}$ analysis), using $\mathrm{CDCl}_{3}$ as solvent. The chemical shifts reported were referenced to the resonances of tetramethylsilane (TMS) or the solvent.

The molecular weight $\left(\mathrm{M}_{\mathrm{n}}\right.$ and $\left.\mathrm{M}_{\mathrm{w}}\right)$ and the polydispersity index (PDI) were measured by gel permeation chromatography (GPC) using a Viscotek GPC equipped with three detectors (LS detector: Viscotek Ralls detector; VS detector: Viscotek Viscometer Model H502; RI detector: Shodex RI-71 Refractive Index detector), using a guard column (PLgel $5 \mu \mathrm{m}$ Guard, $50 \mathrm{~mm}$ ) and two columns (PLgel $5 \mu \mathrm{m}$ MIXED-C, $300 \mathrm{~mm}$, from Agilent Technologies) at $30{ }^{\circ} \mathrm{C}$. Chloroform of HPLC grade was used as the eluent at a flow rate of $1.0 \mathrm{~mL} / \mathrm{min}$. The molecular weight calculations were performed based on the universal calibration. Narrow polydispersity polystyrene standards (Agilent and Polymer Laboratories), with a weight-average molecular weight from 645 to 3,001,000 g/mol, were used to generate the universal calibration curves.

The glass transition temperature and the melting temperature of the co-polyesters were measured by differential scanning calorimetry (DSC) using a TA-Instruments Q1000 DSC. A quench method was conducted for the $\mathrm{T}_{\mathrm{g}}$ measurement. The heating rate was $20^{\circ} \mathrm{C} / \mathrm{min}$.

Thermal gravimetric analysis (TGA) was performed on a Perkin Elmer Thermo Gravimetric Analyzer TGA7. Samples were measured at a scan rate of $10{ }^{\circ} \mathrm{C} / \mathrm{min}$ under nitrogen environment.

\subsection{Calculation of the Molar Composition of PBSI from ${ }^{1} H$-NMR Spectra}

Figure 10. Calculation of the molar composition of PBSI from ${ }^{1} \mathrm{H}-\mathrm{NMR}$ spectra.

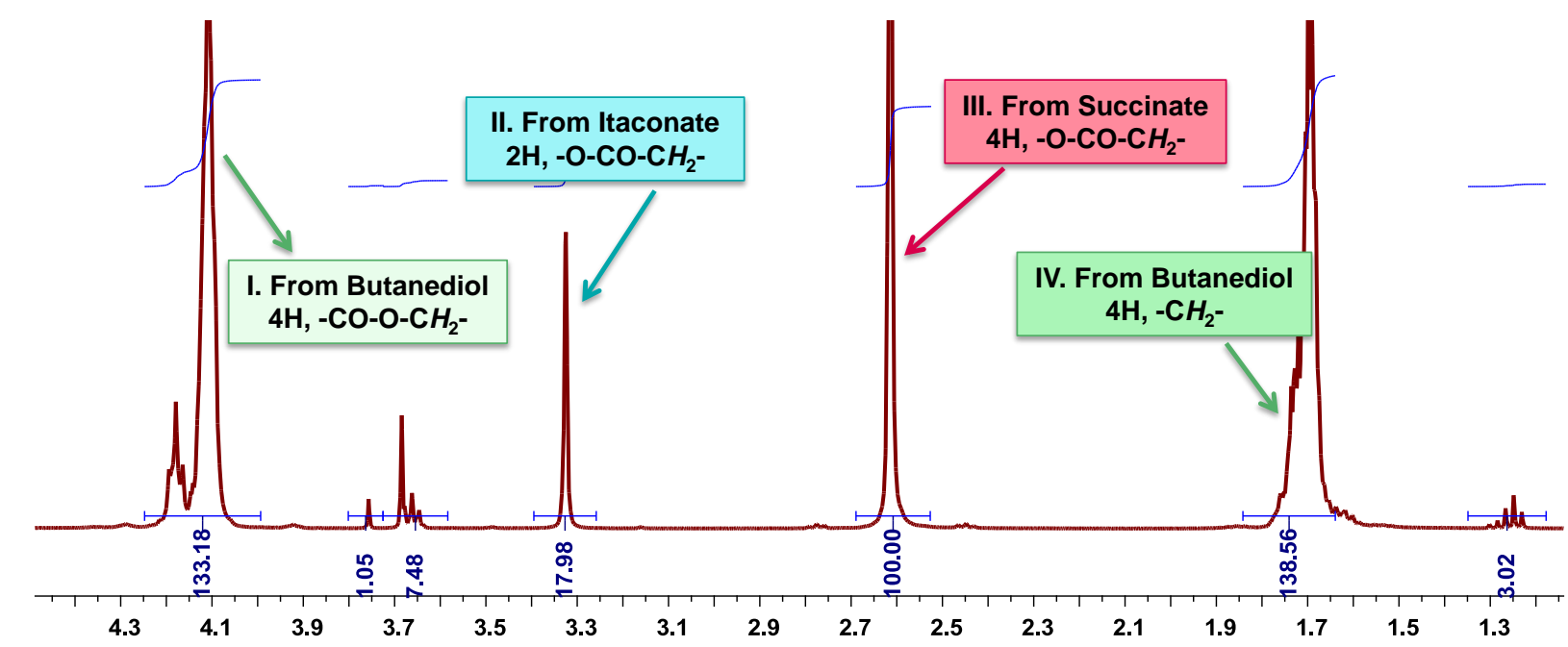

$X_{5}(\%)=\frac{A_{I I} / 4}{A_{I} / 4+A_{I V} / 2+A_{I I} / 4} * 100 \quad X_{I}(\%)=\frac{A_{I V} / 2}{A_{I} / 4+A_{I V} / 2+A_{I I} / 4} * 100 \quad X_{B}(\%)=\frac{A_{I} / 4}{A_{I} / 4+A_{I} / 2+A_{I I} / 4} * 100$ 
The molar composition of PBSI was calculated from ${ }^{1} \mathrm{H}-\mathrm{NMR}$ spectra, as presented in Figure 10 and Equation (1). $\mathrm{A}_{\mathrm{I}}, \mathrm{A}_{\mathrm{II}}$ and $\mathrm{A}_{\mathrm{III}}$ are the integration values of Peak I, Peak II and Peak III, respectively, as displayed in Figure $10 . \mathrm{X}_{S}, \mathrm{X}_{\mathrm{I}}$ and $\mathrm{X}_{\mathrm{B}}$ represent the mole percentage of succinate, itaconate and butylene unit in PBSI.

\subsection{Calculation of the Number Average Molecular Weight of PBSI from ${ }^{1} H$-NMR Spectra}

The number average molecular weight $\left(\mathrm{M}_{\mathrm{n}}\right)$ was characterized from ${ }^{1} \mathrm{H}-\mathrm{NMR}$ spectra, as shown in Figure 11 and Equation (2). $I_{1}, I_{4}$, and $I_{5}$ are the integration values of the peaks assigned to the backbones of PBSI, which are originated from 1,4-butanediol, itaconate and succinate, respectively, as shown in Figure 11. $I_{2}, I_{3}$ and $I_{6}$ are the integration values of the peaks assigned to the end groups.

Figure 11. Calculation of the $M_{n}$ from ${ }^{1} \mathrm{H}-\mathrm{NMR}$ spectra.

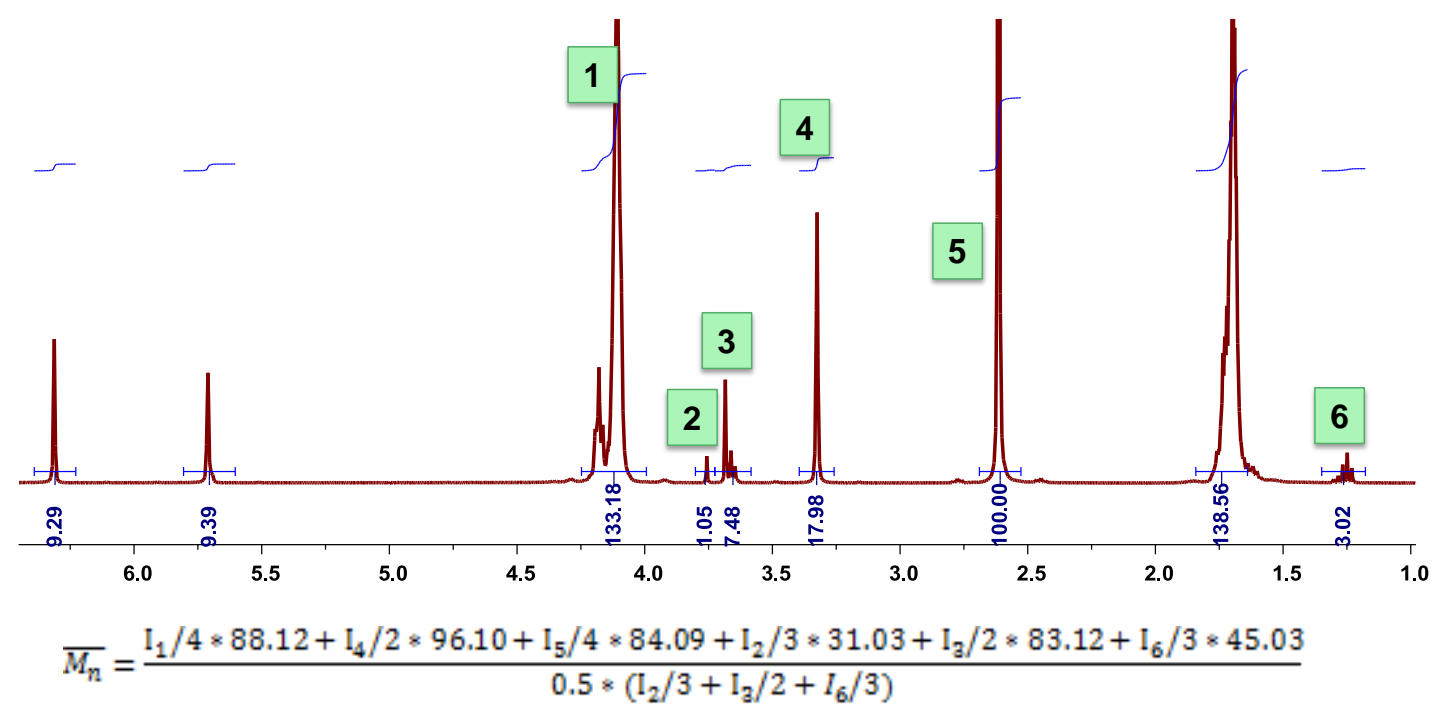

\section{Conclusions}

Fully bio-based poly(butylene succinate) and poly(butylene succinate-co-itaconate) were synthesized by CALB-catalyzed enzymatic co-polymerizations of succinate, itaconate and 1,4-butanediol via the twostage method. It is a totally green approach toward unsaturated aliphatic polyesters, since all the building blocks and catalysts are generated from renewable resources.

The effect of solvent on enzymatic co-polymerization was studied. We found that diphenyl ether was the most suitable solvent, resulting in the highest product $\mathrm{M}_{\mathrm{n}}$ and mole percentage of itaconate, as well as satisfying reaction yields. We believe that such an effect could be attributed to the $\log P$ value of the solvent, the accessibility of CALB in the reaction medium and the solubility of the intermediate and final products in the solvent.

The study on the effect of diphenyl ether dosage indicated that the preferred solvent amount was $150 \mathrm{wt} \%$ (in relation to the total amount of monomers). The $\mathrm{M}_{\mathrm{n}}$, mole percentage of itaconate and reaction yield of PBSI increased with the increase of diphenyl ether dosage first, and then, decreased. The diffusion of the reactants, the residual byproducts amount in the reaction and the polymerization rate are the three factors contributing to such an effect. 
The selected oligomerization time during the first stage had no obvious effects on CALB-catalyzed synthesis of PBSI. The in situ NMR investigations indicated that the oligomerization process was completed after $30 \mathrm{~min}$.

We found that the vacuum during the second stage had a significant influence on enzymatic polycondensation. The best results were achieved under the highest vacuum, since the equilibrium of polycondensation was further shifted to the final products by removing the residual water and alcohols.

The enzymatic polymerizability sequence of itaconate derivatives in diphenyl ether was identified, which was dimethyl itaconate, diethyl itaconate, dibutyl itaconate and itaconic acid, from high to low. The boiling temperature of the reaction byproducts and the accessibility of itaconate to the biocatalyst are two major reasons attributed to this sequence.

With the method here, PBS and a series of PBSI were successfully synthesized with good reaction yields. The amount of itaconate in PBSI was tunable, by adjusting the feed ratio of dimethyl itaconate. The carbon-carbon double bonds of itaconate were well preserved in PBSI. The molecular weight of PBS was lower than that of the unsaturated counterparts, but the PDI was a bit higher.

The values of the product $M_{n}$, mole percentage of itaconate and reaction yield decreased significantly with the increasing of the feed ratio of dimethyl itaconate to $30 \%$. If it was further increased to $35 \%$, or even higher, no product was obtained.

We found that the amount of itaconate in PBSI has no obvious effects on the glass-transition temperature and the thermal stability of the co-polyesters, but has significant effects on the melting temperature. The glass transition temperature of PBS and PBSI was similar, around $-35--38{ }^{\circ} \mathrm{C}$. The temperature of the maximal rate of decomposition remained similar, around $400{ }^{\circ} \mathrm{C}$. However, the melting temperature of the obtained co-polyesters decreased almost linearly as the mole percentage of itaconate in PBSI increased.

\section{Acknowledgments}

This work forms part of the research program of the Dutch Polymer Institute (DPI), \#727c Polymers Go Even Greener. The authors thank Jelena Ćirić and Joop Vorenkamp for the GPC characterizations.

\section{Conflict of Interest}

The authors declare no conflict of interest.

\section{References}

1. Gandini, A. Monomers and macromonomers from renewable resources. In Biocatalysis in Polymer Chemistry; Loos, K., Ed.; Wiley-VCH: Weinheim, Germany, 2010; pp. 1-34.

2. Dove, A. Polymer science tries to make it easy to be green. Science 2012, 335, 1382-1384.

3. Mathers, R.T. How well can renewable resources mimic commodity monomers and polymers? J. Polym. Sci. Pol. Chem. 2012, 50, 1-15.

4. Mülhaupt, R. Green polymer chemistry and bio-based plastics: Dreams and reality. Macromol. Chem. Phys. 2013, 214, 159-174. 
5. Robert, C.; de Montigny, F.; Thomas, C.M. Tandem synthesis of alternating polyesters from renewable resources. Nat. Commun. 2011, 2, e586.

6. Werpy, T.; Petersen, G.R. Top Value Added Chemicals from Biomass Volume I-Results of Screening for Potential Candidates from Sugars and Synthesis Gas; US Department of Energy: Oak Ridge, TN, USA, 2004; pp. 1-67.

7. Bozell, J.J.; Petersen, G.R. Technology development for the production of biobased products from biorefinery carbohydrates - The US Department of Energy's "top 10" revisited. Green Chem. 2010, 12, 539-554.

8. Teramoto, N.; Ozeki, M.; Fujiwara, I.; Shibata, M. Crosslinking and biodegradation of poly(butylene succinate) prepolymers containing itaconic or maleic acid units in the main chain. J. Appl. Polym. Sci. 2005, 95, 1473-1480.

9. Barrett, D.G.; Merkel, T.J.; Luft, J.C.; Yousaf, M.N. One-step syntheses of photocurable polyesters based on a renewable resource. Macromolecules 2010, 43, 9660-9667.

10. Jasinska, L.; Koning, C.E. Unsaturated, biobased polyesters and their cross-linking via radical copolymerization. J. Polym. Sci. Pol. Chem. 2010, 48, 2885-2895.

11. Zhang, Y.-R.; Spinella, S.; Xie, W.; Cai, J.; Yang, Y.; Wang, Y.-Z.; Gross, R.A. Polymeric triglyceride analogs prepared by enzyme-catalyzed condensation polymerization. Eur. Polym. J. 2013, 49, 793-803.

12. Gross, R.A.; Ganesh, M.; Lu, W. Enzyme-catalysis breathes new life into polyester condensation polymerizations. Trends Biotechnol. 2010, 28, 435-443.

13. Mahapatro, A.; Kalra, B.; Kumar, A.; Gross, R.A. Lipase-catalyzed polycondensations: Effect of substrates and solvent on chain formation, dispersity, and end-group structure. Biomacromolecules 2003, 4, 544-551.

14. Albertsson, A.C.; Srivastava, R.K. Recent developments in enzyme-catalyzed ring-opening polymerization. Adv. Drug Deliv. Rev. 2008, 60, 1077-1093.

15. Kobayashi, S. Recent developments in lipase-catalyzed synthesis of polyesters. Macromol. Rapid Commun. 2009, 30, 237-266.

16. Uyama, H.; Kobayashi, S. Enzymatic synthesis of polyesters via polycondensation. In Enzyme-Catalyzed Synthesis of Polymers; Kobayashi, S., Ritter, H., Kaplan, D., Eds.; Springer-Verlag Berlin: Berlin, Germany, 2006; Volume 194, pp. 133-158.

17. Miletic, N.; Loos, K.; Gross, R.A. Enzymatic polymerization of polyester. In Biocatalysis in Polymer Chemistry; Loos, K., Ed.; Wiley-VCH: Weinheim, Germany, 2010; pp. 83-130.

18. Gross, R.A.; Kumar, A.; Kalra, B. Polymer synthesis by in vitro enzyme catalysis. Chem. Rev. 2001, 101, 2097-2124.

19. Miletic, N.; Abetz, V.; Ebert, K.; Loos, K. Immobilization of Candida antarctica lipase B on polystyrene nanoparticles. Macromol. Rapid Commun. 2010, 31, 71-74.

20. Matsumura, S. Enzymatic synthesis of polyesters via ring-opening polymerization. In EnzymeCatalyzed Synthesis of Polymers; Kobayashi, S., Ritter, H., Kaplan, D., Eds.; Springer-Verlag Berlin: Berlin, Germany, 2006; Volume 194, pp. 95-132.

21. Stavila, E.; Alberda van Ekenstein, G.O.R.; Loos, K. Enzyme-catalyzed synthesis of aliphatic-aromatic oligoamides. Biomacromolecules 2013, 14, 1600-1606. 
22. Miletic, N.; Fahriansyah; Nguyen, L.T.T.; Loos, K. Formation, topography and reactivity of Candida antarctica lipase B immobilized on silicon surface. Biocatal. Biotransform. 2010, 28, 357-369.

23. Miletic, N.; Nastasovic, A.; Loos, K. Immobilization of biocatalysts for enzymatic polymerizations: Possibilities, advantages, applications. Bioresour. Technol. 2012, 115, 126-135.

24. Stavila, E.; Arsyi, R.Z.; Petrovic, D.M.; Loos, K. Fusarium solani pisi cutinase-catalyzed synthesis of polyamides. Eur. Polym. J. 2013, 49, 834-842.

25. Stavila, E.; Loos, K. Synthesis of lactams using enzyme-catalyzed aminolysis. Tetrahedron Lett. 2013, 54, 370-372.

26. Binns, F.; Harffey, P.; Roberts, S.M.; Taylor, A. Studies of lipase-catalyzed polyesterification of an unactivated diacid/diol system. J. Polym. Sci. Pol. Chem. 1998, 36, 2069-2079.

27. Binns, F.; Harffey, P.; Roberts, S.M.; Taylor, A. Studies leading to the large scale synthesis of polyesters using enzymes. J. Chem. Soc. Perkin Trans. 1 1999, 2671-2676.

28. Azim, H.; Dekhterman, A.; Jiang, Z.; Gross, R.A. Candida antarctica lipase B-catalyzed synthesis of poly(butylene succinate): Shorter chain building blocks also work. Biomacromolecules 2006, 7, 3093-3097.

29. Habeych, D.I.; Juhl, P.B.; Pleiss, J.; Vanegas, D.; Eggink, G.; Boeriu, C.G. Biocatalytic synthesis of polyesters from sugar-based building blocks using immobilized Candida antarctica lipase B. J. Mol. Catal. B-Enzym. 2011, 71, 1-9.

30. Juais, D.; Naves, A.F.; Li, C.; Gross, R.A.; Catalani, L.H. Isosorbide polyesters from enzymatic catalysis. Macromolecules 2010, 43, 10315-10319.

31. Jiang, Z. Lipase-catalyzed synthesis of aliphatic polyesters via copolymerization of lactone, dialkyl diester, and diol. Biomacromolecules 2008, 9, 3246-3251.

32. Ebata, H.; Toshima, K.; Matsumura, S. Lipase-catalyzed synthesis and properties of poly[(12-hydroxydodecanoate)-co-(12-hydroxystearate)] directed towards novel green and sustainable elastomers. Macromol. Biosci. 2008, 8, 38-45.

33. Kobayashi, T.; Matsumura, S. Enzymatic synthesis and properties of novel biodegradable and biobased thermoplastic elastomers. Polym. Degrad. Stab. 2011, 96, 2071-2079.

34. Tsujimoto, T.; Uyama, H.; Kobayashi, S. Enzymatic synthesis of cross-linkable polyesters from renewable resources. Biomacromolecules 2001, 2, 29-31.

35. Tsujimoto, T.; Uyama, H.; Kobayashi, S. Enzymatic synthesis and curing of biodegradable crosslinkable polyesters. Macromol. Biosci. 2002, 2, 329-335.

36. Uyama, H.; Kuwabara, M.; Tsujimoto, T.; Kobayashi, S. Enzymatic synthesis and curing of biodegradable epoxide-containing polyesters from renewable resources. Biomacromolecules 2003, 4, 211-215.

37. Jiang, Z.; Azim, H.; Gross, R.A.; Focarete, M.L.; Scandola, M. Lipase-catalyzed copolymerization of $\omega$-pentadecalactone with p-dioxanone and characterization of copolymer thermal and crystalline properties. Biomacromolecules 2007, 8, 2262-2269.

38. Mazzocchetti, L.; Scandola, M.; Jiang, Z. Enzymatic synthesis and structural and thermal properties of poly( $\omega$-pentadecalactone-co-butylene-co-succinate). Macromolecules 2009, 42, 7811-7819. 
39. Liu, W.; Wang, F.; Tan, T.; Chen, B. Lipase-catalyzed synthesis and characterization of polymers by cyclodextrin as support architecture. Carbohydr. Polym. 2013, 92, 633-640.

40. Jiang, Z. Lipase-catalyzed copolymerization of dialkyl carbonate with 1,4-butanediol and omega-pentadecalactone: Synthesis of poly-(omega-pentadecalactone-co-butylene-co-carbonate). Biomacromolecules 2011, 12, 1912-1919.

41. MuralidharaRao, D.; Hussain, S.M.D.J.; Rangadu, V.P.; Subramanyam, K.; Krishna, G.S.; Swamy, A.V.N. Fermentatative production of itaconic acid by aspergillus terreus using Jatropha seed cake. Afr. J. Biotechnol. 2007, 6, 2140-2142.

42. Guo, B.; Chen, Y.; Lei, Y.; Zhang, L.; Zhou, W.Y.; Rabie, A.B.M.; Zhao, J. Biobased poly(propylene sebacate) as shape memory polymer with tunable switching temperature for potential biomedical applications. Biomacromolecules 2011, 12, 1312-1321.

43. Wei, T.; Lei, L.; Kang, H.; Qiao, B.; Wang, Z.; Zhang, L.; Coates, P.; Hua, K.-C.; Kulig, J. Tough bio-based elastomer nanocomposites with high performance for engineering applications. Adv. Eng. Mater. 2012, 14, 112-118.

44. Retuert, J.; Yazdanipedram, M.; Martinez, F.; Jeria, M. Soluble itaconic acid ethylene-glycol polyesters. Bull. Chem. Soc. Jpn. 1993, 66, 1707-1708.

45. Ramo, V.; Anghelescu-Hakala, A.; Nurmi, L.; Mehtio, T.; Salomaki, E.; Harkonen, M.; Harlin, A. Preparation of aqueous crosslinked dispersions of functionalized poly(d,l-lactic acid) with a thermomechanical method. Eur. Polym. J. 2012, 48, 1495-1503.

46. Sakuma, T.; Kumagai, A.; Teramoto, N.; Shibata, M. Thermal and dynamic mechanical properties of organic-inorganic hybrid composites of itaconate-containing poly(butylene succinate) and methacrylate-substituted polysilsesquioxane. J. Appl. Polym. Sci. 2008, 107, 2159-2164.

47. Brugel, W.; Demmler, K. Synthesis and properties of itaconic acid-containing polyester resins. J. Polym. Sci. Pol. Sym. 1969, 22, 1117-1137.

48. Sepulchre, M.O.; Sepulchre, M. Synthesis of unsaturated polyesters from dipotassium salts of cis-aconitic, itaconic and mesaconic acids and 1,4-dibromobutane. Macromol. Symp. 1997, 122, 291-296.

49. Rajkhowa, R.; Varma, I.K.; Albertsson, A.C.; Edlund, W. Enzyme-catalyzed copolymerization of oxiranes with dicarboxylic acid anhydrides. J. Appl. Polym. Sci. 2005, 97, 697-704.

50. Linko, Y.Y.; Wang, Z.L.; Seppala, J. Lipase-catalyzed linear aliphatic polyester synthesis in organic-solvent. Enzyme Microb. Technol. 1995, 17, 506-511.

(C) 2013 by the authors; licensee MDPI, Basel, Switzerland. This article is an open access article distributed under the terms and conditions of the Creative Commons Attribution license (http://creativecommons.org/licenses/by/3.0/). 